\title{
Pakistan's Health Care Under Structural Adjustment
}

\author{
Nina Gera*
}

\section{Health Care Under Structural Adjustment}

\section{Abstract:}

The health sector in Pakistan is replete with multifarious problems. It is not responding to the needs of the masses in a way that would provide high-quality care to all in need. Despite the announcements our governments make about health care each year, it limits people's life chances. That international financial institutions claim that state subsidies to health care create undesirable ' market distortions' that benefit the rich is another contradiction faced by the bealth sector. In the name of greater equity and efficiency, they argue that users of primary health care services should pay user fees, even if they are from the impoverished class. These institutions have provided structural adjustment loans to remove shortterm problems. This lending has not contributed to the improvement of bealth facilities. The state has significantly withdrawn itself from health matters: it only spent $0.7 \%$ of GDP in 2000. According to the 1995-96 PIHS the private sector controls $80 \%$ of the health care provisions in Pakistan. Ongoing privatisation of hospitals is likely to strengthen the private sector further. In sum, the neo liberal medicine is not having the desired effect on the health status of the population

It is an international responsibility for nations to protect and promote the health of their populations. The right to health and medical care is widely emphasised in the basic documents of the United Nations and WHO. (Dr Sajjad U Hasan, HRCP Newsletter, April 2002).

The first signs of the emerging right to health are to be found in the Universal Declaration of Human Rights (UDHR). In Article 25 of the Declaration, it is stated that everyone has a right to a standard of living adequate for the health and well being of himself and of his family.' The Declaration further spells out a set of principles to guide countries on how to go about upholding the dignity of mankind.

\footnotetext{
* The author is Asst. Professor, Lahore School of Economics, Lahore.
} 
The 1973 Constitution of Pakistan includes several of the human rights spelt out in the Universal Declaration. In Article 38 it is stated that 'the State shall secure the well being of all people by raising their standard of living and shall provide basic necessities of life, such as food, clothing, housing, education and medical relief for all such citizens as are unable to earn their livelihood by reason of disease, infirmity or unemployment'. This document although recognising the supremacy of civil and political rights, puts greater emphasis on the economic and social rights of people.

Conventional adjustment policies developing countries like Pakistan face have suffered from gross inadequacies. The voiceless, vulnerable majority has had to suffer the brunt of the harsh policies that such adjustment entails. Nutrition and educational levels of children have fallen sometimes drastically, as well as a fall in investment rates. The net result has often been a curtailment of economic growth. Hence the need for alternative adjustment packages. (Cornia, Jolly and Stewart, 1987: 131-3).

As is often the case, global recession as occurred in the 1980s and financial stringency compel governments to cut back on overall expenditure. In the process, social services including health expenditures are the first to be axed considerably. In combination with other policies such as a freeze or reduction in real wages, or the increase in the cost of living and prices of necessities, have a serious effect on the health of the poor, particularly women and children.

But in certain countries it is not inevitable that health conditions deteriorate because of recession or structural adjustment. Governments can and do intervene at such times to improve the health status of the population. The health of a population can be sustained far more by a basic restructuring of social institutions than by financial resources alone.

To state the somewhat obvious, the essential and primary producer of health is the family, particularly the mother. The mother's ability to produce and bring up healthy children will in essence be determined by the resources of the household. It is here that governments can play an active role by influencing household incomes through price and wage determination, and other interventions.

In this framework, physicians, services and drugs are considered to be the inputs while health is the output. Also considered to be an input is social mobilisation and awareness programmes through the media and the school system. 
In other words, health is by no means considered to be a consumer good as per the conventional attitude. Implicit also within this framework is the assumption that expenditures on health are a form of investment and hence productive and leading to national development. Technically qualified manpower forms a considerable chunk of health expenditure but now the philosophy of primary health care and 'health for all' is gaining popularity with many success stories. The challenge for the health sector when adjustment policies are at play is how to change these adjustment constraints into structural changes that can realise these health goals. (Cornia, Jolly and Stewart, 1987:218-224). below:

The question concerns certain priorities for the health sector, listed

1. The need is for a broad based, long term strategy for health in order to gain by multiplier effects from particular health programmes; For instance, safe water supply and sanitation which is an essential ingredient of primary health care, yet does not come under the purview of the Ministry of Health by any yardstick. Safe water and sanitation inevitably require interventions outside the Ministry of Health.

2. Health activities should be undertaken keeping in mind the health needs, infrastructure and basic socio-economic structure of each and every situation.

3. Political will and leadership are indispensable for an effective health programme, to compensate for the marginalisation of the 'voiceless' and the vulnerable.

The dividing line between the demands of human security and of national security throughout South Asia is a very fine one. The former calls for investment in people, while the latter investment in arms. To arrive at a balance between the two is a real problem for policymakers. Until and unless this dilemma is adequately solved, it will not be possible to improve human development in South Asia. The current levels of military spending in South Asia are a serious cause for worry. While the region has nearly 40 per cent of the world's poor, it also manages to spend in the environs of $\$ 14$ billion or more on the military. (Human Development in South Asia, 1997: 80). Soldiers in South Asia outnumber doctors by 6:1, even though people are dying of curable diseases. 
As Cornia, Jolly and Stewart further state, the following basic points need to be pay heed to in order for mortality to be reduced and child health improved when a nation is undergoing structural adjustment:

1. Basic health care can be relatively low cost. For instance in Pakistan, it was observed in the 1980 s that it was feasible and possible to carry out an entire nation-wide immunisation programme from the savings that resulted from not constructing one expensive urban hospital.

Further, if large hospitals were themselves to consciously adopt more cost effective methods and systems, the savings from this would be of a considerable magnitude. Resources could thereby be freed for the provision of basic health services. The need of the hour is hence to make services more cost effective by restructuring health services, which will lead to ensuring the care of a healthy population.

2. The quality of a health programme can improve by leaps and bounds by focusing on the basic components of child survival and development. The widespread introduction of Oral Rehydration Therapy (ORT) is a case in point.

3. Non Government Organisations and political leadership can mobilise the population to participate in health programmes.

\section{South Asian Success Stories}

Sri Lanka and Kerala in India are two instances where the health policies, due to direct action have met with exceptional success. In the case of Sri Lanka, before the 1970s, governmental action in three directions is the essential reason for the relatively salubrious health of the population. These policies included the provision of health facilities, free and compulsory education, and free or subsidised food rations. (Basu in Dreze, Sen and Hussain, 1999:375-380).

Sri Lanka's health record is praiseworthy, with excellent mortality figures resulting from a successful malaria eradication programme on the part of the government in 1946. Compared to most other South Asian countries, the ratio of doctors to nurses to the total population is high.

Vital for the success of any health programme is a certain minimum level of education amongst the population so that people are ready and willing to accept what the government has on offer. Otherwise family planning programmes will fail and people will view vaccination centers as 
torture cells. (Basu in Dreze, Sen and Hussain, 1999: 377) Therefore the other factor that helps explain Sri Lanka's impressive health record is its long history of free education.

How have food rations contributed to better health of the population? This has taken the form of providing a certain amount of free rice and sometimes wheat, as well as additional rations at a subsidised price. Consequently, Sri Lanka's daily calorie intake is much higher than that of other South Asian countries.

Similar circumstances prevail in Kerala, a state that has proved that improvements in standards of living are not necessarily a function of growth. Educational performance is remarkable and health facilities are better distributed, all as a result of progressive government policies. Food rationing where food items are distributed at subsidised rates, exist in both urban and rural areas.

In the final analysis then is there a trade off between equity and growth? Although we will not delve on the issue here, Kaushik Basu (in Dreze, Sen and Hussain, 1999:382-4) optimistically argue that most LDCs are operating below their possibility frontiers and hence there is sufficient slack for them to enjoy more of both equity and growth.

\section{Pakistan's Case}

Zaidi claims that health services in Pakistan are highly inequitable and urban biased, based on a western oriented curative care model.. (Zaidi, 1988:123-32)

The 1978 Alma Ata declaration on 'Health for all by the Year 2000' has nowhere near been realised in Pakistan and is still a far cry. The need is for a new model of health care that will indigenise health care and make it available to all citizens of the country. The emphasis ought to be on preventive rather curative health care and the urban bias should be remedied.

Pakistan's health care system typifies many postcolonial Third World countries, although there are features that are specific to it. The health care model has barely changed since British rule being doctor oriented, curative rather than preventive and urban biased in terms of resources and personnel. Although the population per doctor has fallen from 11,133 in 1976 , to 1,529 in 2000 this improved ratio is nowhere near adequate in terms of improving the health status of the population. Similarly, in expenditure terms government expenditure on health increased from Rs 
979.2 million in 1976 to Rs 24,281 million in 2000 , the increase in real terms and as a percentage of GDP has been extremely low. What with the private sector playing the dominant role, it is highly inequitable, where the ruling criterion is ability to pay rather than need. (Zaidi, 2001:279). Since the private health care system has virtually taken over, the public health care system has been seriously undermined. The end result is that the health status of the population is nowhere what it should be given the level of development as measured by per capita income.

The picture could have been far grimmer had there not been the vast inflow of money from the Middle East remitted by workers from 1977 to 1988. (Zaidi, 2001:281-2 ). A considerable portion of these remittances was spent on small-scale employment and house improvements which led to better, more hygienic and healthier living conditions. In any event health indicators are still pathetically low especially when compared to other lowincome countries.

Health policies in Pakistan have almost throughout reflected the conditionalities of the donor agencies. In the World Bank's World Development Report 1993, a lucid statement is made with regard to LDCs' reforms in the health sector. Government inefficiency and corruption receive a great deal of flak as well as heavy expenditures on curative medicine and specialised health training that ends up subsidising the rich. The slant presented is to shift from tertiary medicine to primary health care. As Khan points out, all this give the Bank the appearance of a $60 \mathrm{~s}$ radical, but that is not the case since radical proposals and the Bank's well intentioned measures are in fact quite at odds with each other.

The Bank's main thrust in keeping with its overall outlook is to minimise the government's role and give free play to the market and the private sector. Privatisation is the buzzword, the idea being to 'get prices right'. However, this is not without qualifications as the Bank does see an important role for the government in disease control and dietary supplement programmes. Related to this is the government's role in disseminating information on disease control. (Khan, 1999:138-40)

The idea is to curtail government expenditure on health by cutting down on subsidies and inessential services and improving services via decentralisation. Cuts in government recurring expenditure will lower recruitment in the public sector including the health sector and cuts in capital expenditure will either terminate or slow down the process of expansion of health facilities. As with other private sector institutions, private medical colleges are mushrooming and are in for boom times. They 
charge the students market tuition rates unlike public sector institutions. This will only lead to more doctors in a doctor dominated health care system who will charge exorbitant consultation fees in order to make some returns on their investments in educating themselves. (Zaidi, 2001:287-8) Given the conditionalities of the structural adjustment programmes, there is a strong likelihood that the public sector will no longer act as a provider of health care, especially primary and secondary level care. Its only role will be to ensure an 'enabling environment' so that the private sector can function without hurdles. It is intended that encouraging competition and allowing the private sector to deliver health services and inputs such as drugs and medical equipment will further reduce costs. User fees are recommended for the recovery of costs.

It is in essence a three-pronged approach. Macro stabilisation leads to improved growth, that enhances the incomes of the poor and that in turn will enable them to invest more on health. To sum up, the Bank advocates a minimal role for the government to avoid inefficiency and corruption and the promotion of diversity and competition. The Bank has been widely criticised for its health reforms on the grounds that its concept of primary health care is far too narrow and restricted, and that by promoting the private sector in health care, the government is abdicating its responsibility as a provider of basic human needs.

Pakistan's health policy of 1997, like those that came later, follows the Bank's reform agenda in letter and spirit. The private sector takes on the primary responsibility in the areas of family planning, preventive services and drugs. Likewise Basic Health Units and Rural Health Centres were to be contracted out to private health physicians and lastly, autonomy would be granted to certain hospitals and they would be permitted to levy user charges. The outcome of granting autonomy to these hospitals was that the services provided have become more expensive, making them unaffordable for the poor.

Even till the present, it is often the poor who have to wait in long queues as against the relatively well off who simply jump the queue or go to a specialist by paying exorbitant fees in private clinics. No new public hospitals are in the pipeline. Today in Pakistan, the medical profession is a flourishing profession, amongst the most lucrative that exists. The increase in the number of doctors being insufficient for the population even now and the shortage of specialists has led to a monopolistic situation where they can charge higher fees and get away with it. 
The budgetary allocation for the health sector in the Budget 20022003 has been increased by Rs 790 million in which Rs 3.3 billion has been earmarked against the previous year's allocation of Rs 2.513 billion. The health policy this time round focuses on the preventive side, an attempt to shift from urban to rural areas and emphasis on mother and child health. Lady Health Workers are to be the prime movers of preventive health as is also the expanded programme of immunisation. The total number of Lady Health Workers is now to number nearly 65,000 and the outreach of the programme has been expanded to nearly 65 million people that is almost half the country's population. The coverage of the expanded programme of immunisation is to be increased from five per cent to 55 per cent.

Since the initiation of structural adjustment programmes, the very nature of the economy has altered as well as the overall impact on health status, health care and welfare in general. Moreover, under the conditionalities of the $\mathrm{WB} / \mathrm{IMF}$, phenomena such as rising unemployment, fall in per capita incomes and increasing poverty forms a lethal mix that prevents the poor from improving their health. Thus attempts such as the Social Action Programme initiated and later disbanded by the government can at the best of times have only a marginal impact.

The government's priorities have also been misplaced. Population control measures are part and parcel of conditionalities and popular with most donor agencies. This accentuated focus on family planning stems from the theory, now not so current, that burgeoning population is the root cause of poverty. Giving population control so much attention leads to eroding health expenditure allocation and also disadvantages the primary health care structure. (Bennet, 2001:59-60). Family planning programmes were initiated in Pakistan in the late fifties and since then to date enormous amounts have been spent on it with relatively little success. It is only of late that the annual population growth rate has been brought down to 2.16 per cent (Economic Survey, 2001-2002).

Emphasis has mostly been on contraceptive use while female morbidity is largely attributed as an outcome of high fertility and is more or less turned a blind eye to. It has to be recognised that maternal and child health, albeit a matter of reproductive health, the actual cause is invariably lack of medical care and poor living conditions which lead to infectious and parasitic diseases. In the final analysis simply expanding the supply of contraceptives with little or no consideration of demand factors and low socio economic development will only marginally impact on fertility. The key is to invest in human development capital such as housing, transport, 
safe drinking water supply, and sanitation and last but not least, accessibility to health services. (Bennet, 2001:60-1).

\section{Taxes and Drugs}

The provision of essential drugs is not necessarily an expensive exercise if handled with care and in a proper manner as part of a national policy. Adequate supply for all can be ensured at an affordable cost.

Yet it is one of the ironies of fate that in March 2002, the government seriously contemplated imposing a tax on medicines so as to fulfill an IMF conditionality. It was intended to be a 15 per cent General Sales Tax on all medicines and drugs that consequently was opposed by all and sundry, be it the pharmaceutical industry, the drug trade and by consumers themselves. As it is, the price of medicines is comparatively higher in Pakistan in general than neighbouring India, and threatens to drive out the poor from the health care system, but the middle class is badly affected as well.

In the face of opposition from the public, the government decided in late March to withdraw the GST on life saving drugs. The GST on other medicines remained intact, because the government justified its actions on the grounds that it cannot be avoided due to certain 'compulsions', a reference to IMF conditionalities.

In the first instance the $15 \%$ GST had been in place in any case, but exemptions were allowed. It was proposed to remove these exemptions. Oddly enough, the buyer paid the tax levied on the seller.

It was hoped that the GST on medicines would generate a total revenue of Rs 4 billion, and that would supposedly be used to provide health care facilities for the poor. Knowing Pakistan's track record, the more likely outcome would be that of corruption.

Tragically, drug prices have been steadily increasing over the last several years. Not just the pharmaceutical companies and the health bureaucracy, but the governments as well have allowed such increases. In the years to come, it is likely that all subsidies, controls and exemptions will be removed under the philosophy of deregulation. The future of health care for the poor therefore decidedly looks bleak, unless something drastic is undertaken to remedy the situation. 
Much to everyone's surprise, the 15 per cent GST was withdrawn on all kinds of medicines in August 2002. The reason being as stated by the Finance Minister that it was 'causing hardship' to a number of people. It was admitted that it had been a mistake and that the government had decided to rectify it. However, what will happen in the years to come is anyone's guess.

In a sense global economic recessions such as that of the 1980s have their silver lining apart from their dark side in that they compel nations to critically evaluate their national priorities. Such a critical perception is imperative in the health sector. Under any circumstance health expenditures should be regarded as investment that improves the quality of human capital. And without political will and leadership, it is not possible to ensure 'adjustment with a human face'.

\section{Econometric Analysis}

Our hypothesis was that structural adjustment loans have not played a significant role in any sense in improving the health status of the population, the infant mortality rates in particular. In order to test this hypothesis, regression analysis was used.

Infant mortality and child mortality rates are the basic indicators of the health status of the population. In Pakistan, infant and child mortality rates have declined over the recent past, but are still high even when compared to other South Asian countries, except Bhutan. Regression analysis was carried out using OLS techniques to discover the relationship between the infant mortality rate and variables such as per capita income, government expenditure on health, remittances, and structural adjustment loans received over the period 1976-77 to 2000-2001.

As the data is time series, the stationarity of the data was checked for all the variables and found that the data was non-stationary and had a trend for per capita income and expenditure on health. In order to remedy the problem, the data was differenced by one period to make the series stationary. The variables were found to be co integrated so the original data was regressed.

The results are given below:

$$
\begin{aligned}
& \mathrm{i}=71.02+0.01 \text { py }+1.8 \mathrm{r}-0.16 \mathrm{eh}-0.171 \\
& \mathrm{t}=(9.93)
\end{aligned}
$$


$\mathrm{R}^{2}=0.7 \quad \mathrm{DW}=2.09 \quad \mathrm{~F}=11.6$

where

$\mathrm{i}=$ infant mortality

py $=$ per capita income

$r=$ remittances

eh $=$ govt expenditure on health

$1=$ structural adjustment loans

Per capita income is taken as a proxy for personal household expenditures on health. (Zaidi, 1997: 7) Infant mortality is positively related to per capita income. It is negatively related to government expenditure on health and conditional loans. Contrary to the World Bank view, public sector health expenditures prove to be very effective in reducing the infant mortality rate. The fact that there is a positive relationship between remittances and infant mortality is probably because the money from remittances was not utilised for health care expenses but on consumer durable items instead.

The Durbin Watson statistic shows no problem of autocorrelation. The value of $R^{2}$ is also quite high, indicating that the model is good. The $t$ values show that our explanatory variables except remittances are statistically significant.

Another regression was run for life expectancy at birth. The explanatory variables were per capita income, government expenditure on health, remittances and structural adjustment loans. The data for life expectancy at birth, per capita income and expenditure on health was non stationary so the differenced data was used. The data used in this econometric analysis is given in Tables 1 and 2. The results were as follows:

Leab $=57.56-0.0046$ py +.36 eh $-0.075 r-0.0011$

$\mathrm{t}=(32.6) \quad(-.67) \quad(3.7) \quad(-0.09) \quad(-0.55)$

$\mathrm{R}^{2}=.76$

$\mathrm{DW}=2.8$ 
Where:

Leab $=$ life expectancy at birth

py $=$ per capita income

eh $=$ expenditure on health

$\mathrm{R}=$ remittances

$\mathrm{L}=$ structural adjustment loans

There is no problem of autocorrelation. The parameters of income and expenditure on health are statistically significant.

The model shows that there is a negative relationship between per capita income and life expectancy. In other words, although average income has gone up, life expectancy decreases. This is explained by Khan (1999) that if income distribution is very uneven and the growth process neutral to or accentuating inequalities, higher per capita GDP does not necessarily result in improved health indicators. A nominal increase in income of the poor leads to the likelihood that this income group will spend more on food, clothing and shelter rather than the health of themselves and their families. Hence the anomaly.

There is a positive relationship between government expenditure on health and life expectancy at birth. It simply proves the point, contrary to donor thinking that public expenditure on health has a positive impact on the health status of the population.

In the regression analysis regressions on life expectancy and infant mortality against services/facilities available for the poor, for instance basic health units, doctors per head of the population, number of lady health visitors etc. were also run. It was felt that such variables are more likely to impact on the health status of the poor. However, it was found to be statistically insignificant and the relationships between the parameters and the dependent variable were negative. This can be explained by the fact that for the poor, nutrition levels and quality of services are more important factors that determine the life expectancy and overall health status of the poor.

The data indicates that infant mortality has gone down from 115 per thousand people in 1983-4 to 85 per thousand in 2001-2 and life expectancy over time has increased from 53 in 1977-8 to 63 in 2001-2, but 
compared to other Asian countries the improvements have not been good (See Table 3).

Usually there is a positive correlation between economic growth and human development indicators, including health status of the population. But with economic growth decelerating and virtually coming to a standstill, the situation is far worse with the conditions imposed by structural adjustment programmes. It is apparent that privatisation, cuts in government spending, 'getting prices rights' and more market oriented poilices, have all adversely affected the health of the people. The advocates of structural adjustment programmes including its spokespersons in the government insist on the fact that 'free markets' will one fine day nurture development in Third World countries. This totally goes against the realities on the ground in these economies. With the poor becoming poorer the situation will only be further exacerbated. Under such circumstances one simply questions the state's pronouncements for promoting health and making health care more affordable and accessible. People-centred development, self reliant growth and an equitable distribution of resources can only flourish when there is a paradigmatic policy change from efficiency and competitiveness to employment creation and poverty alleviation. 
The Lahore Journal of Economics, Vol.8, No.2

TABLE 1: Time Series Data on Variables Regressed

\begin{tabular}{|c|c|c|c|c|}
\hline Time series & $\begin{array}{l}\text { Infant } \\
\text { Mortality } \\
\text { Per } 1000 \\
\text { persons }\end{array}$ & $\begin{array}{l}\text { Life } \\
\text { Expectancy } \\
\text { at birth (per } \\
\text { 1000) }\end{array}$ & $\begin{array}{l}\text { Population } \\
\text { per Doctor }\end{array}$ & $\begin{array}{l}\text { Government } \\
\text { exp. on Health } \\
\text { (Rs. M.) }\end{array}$ \\
\hline $1976-77$ & 87 & 59 & 11133 & 979.2 \\
\hline $1977-78$ & 100 & 53 & 10278 & 1070.6 \\
\hline $1978-79$ & 95 & 59 & 9526 & 1210.6 \\
\hline $1979-80$ & 95 & 56 & 8695 & 1378.9 \\
\hline $1980-81$ & 100 & 55 & 7549 & 1736.8 \\
\hline $1981-82$ & 110 & 56 & 6101 & 2030.1 \\
\hline $1982-83$ & 112 & 56 & 5087 & 2390 \\
\hline $1983-84$ & 115 & 57 & 4308 & 3090 \\
\hline $1984-85$ & 126.7 & 57 & 3605 & 3372.1 \\
\hline $1985-86$ & 115.9 & 57 & 3160 & 4275.3 \\
\hline $1986-87$ & 105.6 & 59 & 2865 & 5852 \\
\hline $1987-88$ & 103.9 & 58 & 2594 & 7178.4 \\
\hline 1988-89 & 107.7 & 58 & 2396 & 7321 \\
\hline $1989-90$ & 106.7 & 58 & 2228 & 7218 \\
\hline $1990-91$ & 107.7 & 59 & 2082 & 7738 \\
\hline $1991-92$ & 107.7 & 54.3 & 1993 & 8531.6 \\
\hline $1992-93$ & 108 & 60 & 1892 & 9604.6 \\
\hline 1993-94 & 104.7 & 60.2 & 1848 & 10555 \\
\hline $1994-95$ & 101.8 & 59.3 & 1803 & 12090.7 \\
\hline $1995-96$ & 101.8 & 61 & 1455 & 16354.9 \\
\hline $1996-97$ & 101.8 & 62.4 & 1689 & 18342.8 \\
\hline $1997-98$ & 84.4 & 62 & 1636 & 19663.5 \\
\hline 1998-99 & 85.5 & 63.2 & 1590 & 20807.7 \\
\hline $1999-2000$ & 89.8 & 63 & 1578 & 22077 \\
\hline $2000-2001$ & 90 & 62.5 & 1529 & 24281 \\
\hline 2001-2002 & 85 & 63 & 1516 & 25405 \\
\hline
\end{tabular}

Source: Economic Survey, Various Issues, Government of Pakistan 
TABLE 2: Time Series Data on Variables Regressed

\begin{tabular}{|c|c|c|c|}
\hline Time series & $\begin{array}{l}\text { Workers } \\
\text { Remittances } \\
\text { (U.S. \$ b.) }\end{array}$ & $\begin{array}{l}\text { Per Capita } \\
\text { Income (1980-81) }\end{array}$ & $\begin{array}{l}\text { IMF Structural } \\
\text { Adjustment } \\
\text { Loans }\end{array}$ \\
\hline $1976-77$ & 0.58 & 1790 & 0 \\
\hline $1977-78$ & 1.15 & 2117 & 48 \\
\hline $1978-79$ & 1.40 & 2300 & 71 \\
\hline $1979-80$ & 1.74 & 2648 & 157.4 \\
\hline $1980-81$ & 2.11 & 3326 & 16.1 \\
\hline $1981-82$ & 2.22 & 3441 & 349 \\
\hline $1982-83$ & 2.89 & 3570 & 730 \\
\hline $1983-84$ & 2.74 & 3700 & 80 \\
\hline $1984-85$ & 2.44 & 3819 & 0 \\
\hline $1985-86$ & 2.59 & 3900 & 0 \\
\hline $1986-87$ & 2.28 & 4067 & 0 \\
\hline $1987-88$ & 2.01 & 4264 & 0 \\
\hline 1988-89 & 1.90 & 4358 & 194.48 \\
\hline $1989-90$ & 1.94 & 4432 & 273.15 \\
\hline $1990-91$ & 1.85 & 4552 & 150 \\
\hline $1991-92$ & 1.47 & 4826 & 0 \\
\hline $1992-93$ & 1.56 & 4778 & 0 \\
\hline $1993-94$ & 1.44 & 4813 & 88 \\
\hline $1994-95$ & 1.87 & 4951 & 60 \\
\hline $1995-96$ & 1.46 & 5016 & 80.55 \\
\hline 1996-97 & 1.40 & 4927 & 101.10 \\
\hline $1997-98$ & 1.49 & 4924 & 250 \\
\hline 1998-99 & 1.06 & 4992 & 350 \\
\hline $1999-2000$ & 0.98 & 5073 & 0 \\
\hline $2000-2001$ & 1.09 & 5098 & 350 \\
\hline 2001-2002 & 1.87 & 5294 & 0 \\
\hline
\end{tabular}

Source: Economic Survey, Various Issues, Government of Pakistan 
80 The Lahore Journal of Economics, Vol.8, No.2

Table 3: Selected Health Indicators 1999

\begin{tabular}{llll}
\hline & $\begin{array}{l}\text { Life Expectancy at } \\
\text { Birth (years) }\end{array}$ & $\begin{array}{l}\text { Infant Mortality } \\
\text { rate per 1000 }\end{array}$ & $\begin{array}{l}\text { Population } \\
\text { Growth (annual } \\
\text { percent) }\end{array}$ \\
\hline Pakistan & 62.5 & 89.8 & 2.4 \\
India & 63.2 & 70.9 & 1.8 \\
Bangladesh & 60.7 & 61.2 & 1.6 \\
Sri Lanka & 73.5 & 15.4 & 1.1 \\
Nepal & 58.2 & 75.4 & 2.3 \\
Bhutan & 61.5 & 58.8 & 2.9 \\
Thailand & 68.6 & 28.3 & 0.8 \\
Malaysia & 72.3 & & 2.4 \\
Indonesia & 65.7 & 30.2 & 0.9 \\
China & 70.1 & & \\
\hline
\end{tabular}

World Development Indicators, July 2000 


\section{References}

Banuri, Tariq, Shahrukh Rafi Khan, Moazam Mahmood, Just Adjustment, Beyond Adjustment with a Human Face, Oxford University Press, Karachi, 1997.

Bennet, Jennifer, 2001 "Structural Adjustment and the Poor in Pakistan," in Public Health and the Poverty of Reforms ed. Imrana Qadeer, Kasturi Sen, and K R Nayar, Sage Publications, New Delhi,.

Bokhari, Ashfak, Taxing the Distressed, Daily Dawn, April 1-7,. 2002

Cornia, Giovanni Andrea, Richard Jolly and Frances Stewart 1987, Adjustment with a Human Face, Protecting the Poor and Vulnerable, UNICEF Report, Clarendon Press, Oxford,.

Basu, Kaushik in Dreze, Jean, Amartya Sen and Athar Hussain (Ed), 1999. The Political Economy of Hunger, Oxford University Press, New Delhi,.

Khan, Shahrukh Rafi, 1999. Do World Bank and IMF Policies Work? Macmillan Press Ltd, Basingstoke and St Martin's Press, Inc., New York,.

Mohan, Giles, Ed Brown, Bob Milward and Alfred B Zack-Williams, 2000 Structural Adjustment, Theory, practice and impacts, Routledge, London and New York,.

Tahir, Pervez and Sara Fatima, Social and Economic Development - A Rights Puzzle, in The Lahore Journal of Economics, Vol 6, No 1, Jan-June 2001.

Zaidi, Akbar, S., 1988 The Political Economy of Health Care in Pakistan, Vanguard, Lahore, Islamabad, Karachi,.

Zaidi, Akbar, S., 2001 Structural Adjustment and Economic Slowdown: Likely Impact on Health Outcomes in Pakistan, in Public Health and Poverty of Reforms, eds. Imrana Qadeer, Kasturi Sen and K R Nayar, Sage Publications, New Delhi,

The Budget, 2002-2003, Government of Pakistan, Islamabad.

Pakistan Economic Survey, various issues, Government of Pakistan, Islamabad. 